\title{
Educational Levels and Risk of Suicide in Japan: The Japan Public Health Center Study (JPHC) Cohort I
}

\author{
Takashi Kimura $^{1}$, Hiroyasu Iso ${ }^{1}$, Kaori Honjo ${ }^{2}$, Satoyo Ikehara ${ }^{1,3}$, Norie Sawada ${ }^{4}$, \\ Motoki Iwasaki ${ }^{4}$, and Shoichiro Tsugane ${ }^{4}$, for the JPHC Study Group \\ ${ }^{1}$ Public Health, Department of Social Medicine, Osaka University Graduate School of Medicine, Suita, Osaka, Japan \\ ${ }^{2}$ Global Collaboration Center, Osaka University, Suita, Osaka, Japan \\ ${ }^{3}$ Department of Hygiene and Public Health, Osaka Medical College, Takatsuki, Osaka, Japan \\ ${ }^{4}$ Epidemiology and Prevention Group, Research Center for Cancer Prevention and Screening, National Cancer Center, Tokyo, Japan
}

Received December 9, 2014; accepted September 16, 2015; released online April 9, 2016

Copyright $\subseteq 2016$ Takashi Kimura et al. This is an open access article distributed under the terms of Creative Commons Attribution License, which permits unrestricted use, distribution, and reproduction in any medium, provided the original author and source are credited.

\begin{abstract}
Background: Suicide rates have been related to educational level and other socioeconomic statuses. However, no prospective study has examined the association between educational level and the risk of suicide in Japan.

Methods: We examined the association of education level and suicide risk in a population-based cohort of Japanese men and women aged 40-59 years in the Japan Public Health Center-based Prospective Study Cohort I. In the baseline survey initiated in 1990, a total of 46156 subjects (21 829 men and 24327 women) completed a selfadministered questionnaire, which included a query of educational level, and were followed up until the end of December 2011. Educational levels were categorized into four groups (junior high school, high school, junior or career college, and university or higher education). During a median follow-up of 21.6 years, the hazard ratios (HRs) and $95 \%$ confidence intervals (CIs) of suicide according to educational level were estimated using the Cox proportional hazards regression model adjusted for age; study area; previous history of stroke, ischemic heart disease, or cancer; self-reported stress; alcohol consumption; smoking; living with spouse; and employment status. A total of
\end{abstract} 299 deaths attributed to suicide occurred.

Results: The HR for university graduates or those with higher education versus junior high school graduates was 0.47 (95\% CI, 0.24-0.94) in men, and that for high school graduates versus junior high school graduates was 0.44 (95\% CI, 0.24-0.79) in women.

Conclusions: High educational levels were associated with a reduced risk of suicide for both Japanese men and women.

Key words: suicide; education; socioeconomic status; prospective study

\section{INTRODUCTION}

Suicide is a serious global public health issue. Every year, more than 800000 people die from suicide. ${ }^{1}$ In Japan, from 1996 to 2012, the death rate from suicide was approximately 20 per 100000 individuals, with the highest rate in 1998 of over 50 per 100000 among men aged 45 to 64 years. ${ }^{2}$

Previous studies have indicated that the risk of suicide varies with socioeconomic status, ${ }^{3-7}$ especially with respect to income,${ }^{8}$ occupation, ${ }^{9,10}$ living arrangement, ${ }^{11}$ and educational level. ${ }^{12-15}$ These associations suggest that suicide is induced by socioeconomic factors as well as biological, psychological, and lifestyle factors and the presence of illness. We considered educational level to serve as a surrogate marker for socioeconomic status. In general, college graduates or those with advanced degrees gain greater public respect compared to those with less education, regardless of their occupational positions. ${ }^{16}$ Still, educational levels are correlated strongly with occupation and income and remain stable over an individual's lifetime. ${ }^{17}$ Effects from an individual's economic change or the shifting of employment status in later life may be small due to the relatively stable employment system in Japan, but such a situation is not necessarily true in other countries.

However, research on the association between an individual's educational level and suicide risk has been limited and inconclusive. According to a previous cohort 
study in the United States, compared with higher levels of education, high school graduation and lower levels of education are associated with a higher risk of suicide in men but not in women, after adjustment for race, ethnicity, geographic variables, marital status, and employment status. ${ }^{12}$ A European comparative cohort study indicated that the lower educational categories (International Standard Classification of Education [ISCED] 1 and 2) are generally associated with a higher risk of suicide than the higher categories (ISCED 3+) in men, whereas the higher categories (ISCED 3+) are weakly but significantly associated with a higher risk of suicide in women. $^{13}$

An Italian nationwide registry study showed a significant difference in the educational attainments between suicide victims and persons with natural causes of death. For both men and women, persons who died from suicide were more likely to have higher educational attainment than those who died from natural causes. ${ }^{14}$ However, this finding should be interpreted with caution, because deaths from natural causes were used as a reference. On the other hand, a Japanese autopsy study, using 145 gender-, age-, and municipalitymatched living controls, showed that $28.6 \%$ of suicide completers and $16.6 \%$ of living controls had low educational attainment ( $\leq 11$ years). ${ }^{15}$ These inconsistent results may be in part due to different educational and occupational systems among countries.

In response to the discrepancy of previous findings, we examined the association between educational levels and the risk of suicide in a large prospective cohort study of approximately 45000 Japanese adults.

\section{METHODS}

\section{Study cohort}

The Japan Public Health Center-based Prospective Study (JPHC study) is a population-based cohort study conducted since 1990 among 61595 individuals (29980 men and 31615 women aged 40 to 59 years) who registered their addresses in 15 administrative districts supervised by five public health center areas in Cohort I. The study design has been described in detail elsewhere. ${ }^{16}$

A total of 23584 men (79\%) and 26661 women (84\%) responded to the baseline questionnaire. We excluded 28 people because of ineligibility ( 7 non-Japanese and 21 Japanese who moved away before the start of the study). Additionally, we excluded 4061 people (1742 men and 2319 women) who did not report valid information on educational level from the analysis. Ultimately, 46156 subjects (21 829 men and 24327 women) were used for the present analysis. Information on the study purpose and methods for the baseline and follow-up is disclosed on the JPHC website (http:// epi.ncc.go.jp/jphc/). The study protocol was approved by the Institutional Review Board of the National Cancer Center and the Osaka University, Japan.

\section{Assessment of educational levels and covariates}

The study participants completed a self-administered questionnaire, which included a query of educational levels. The Japanese educational system consists of 6 years of elementary school and 3 years of junior high school, which are compulsory education. As for elective education, there are 3 years of high school, 2 years of junior college, 2 or 3 years of career college, and 4 years of university. In our study, educational levels were categorized as graduation from junior high school, high school, junior college, career college, and university or higher education. We also inquired about personal and familial medical histories, smoking habit, habitual intake of foods and beverages (including alcohol), physical activity, perceived stress levels, living arrangement, occupation, and other lifestyle factors.

\section{Follow-up and identification of suicide}

The study participants were followed from the start of the study in 1990 until December 31, 2011. The residential registry in each area was reviewed annually to obtain information on changes in residential status, including survival. The status of subjects who had moved out of the study area was assessed through the municipal office of the area to which they had moved. Mortality data for persons under the residential registry were forwarded to the Ministry of Health, Labour and Welfare and coded for inclusion in the National Vital Statistics.

Information on the deaths of the subjects who remained in the original area was obtained from local public health centers (PHCs); information on the deaths of the subjects who died after moving from their original PHC area was obtained from death certificates maintained by the Ministry of Health, Labour and Welfare, Japan. The cause of death was also obtained from the Ministry of Health, Labour and Welfare with the permission of the Ministry of Internal Affairs and Communications. Suicidal death was defined according to the International Classification of Diseases, 10th Revision (ICD-10; codes X60 to X84).

\section{Statistical analysis}

The number of person-years in the follow-up period was calculated from the date of response to the baseline questionnaire to the date of death or December 31, 2011, whichever came first. The hazard ratios (HRs) and 95\% confidence intervals (CIs) were calculated according to the categories of graduates from high school, junior or career college, and university or higher education, with junior high school graduates as a reference, using Cox proportional-hazard models. The statistical power under the condition of $\alpha=0.05$ (two-tailed) and an HR of 0.5 was $80.1 \%$.

We calculated HRs of suicide adjusting for age and study areas. Then, we adjusted further for previous history of stroke, ischemic heart disease, or cancer (yes/no); self-reported stress (mild, moderate, or high); alcohol consumption (non-, occasional, or current drinker); smoking habit (never, ex-, or 
Table 1. Distributions of baseline characteristics according to educational levels

\begin{tabular}{|c|c|c|c|c|c|}
\hline & \multicolumn{5}{|c|}{ Educational levels } \\
\hline & $\begin{array}{l}\text { Junior high } \\
\text { school }\end{array}$ & High school & $\begin{array}{c}\text { Junior or career } \\
\text { college }\end{array}$ & $\begin{array}{l}\text { University or higher } \\
\text { education }\end{array}$ & $P$ for trend \\
\hline \multicolumn{6}{|l|}{ Men } \\
\hline Number of subjects & 10350 & 8437 & 1074 & 1968 & \\
\hline Age, years & 50.5 & 48.1 & 47.5 & 46.7 & $<0.001$ \\
\hline Previous history of stroke, ischemic heart disease, or cancer, \% & 3.6 & 3.0 & 2.8 & 2.3 & $<0.001$ \\
\hline Current drinker, $\%$ & 64.3 & 69.3 & 65.1 & 65.9 & 0.006 \\
\hline Current smoker, \% & 54.9 & 53.1 & 51.0 & 47.0 & $<0.001$ \\
\hline High perceived mental stress, $\%$ & 20.0 & 29.3 & 33.9 & 43.8 & $<0.001$ \\
\hline Living with spouse, $\%$ & 76.0 & 86.4 & 87.9 & 90.6 & $<0.001$ \\
\hline Full-time worker, \% & 96.0 & 97.4 & 97.8 & 97.8 & $<0.001$ \\
\hline \multicolumn{6}{|l|}{ Women } \\
\hline Number of subjects & 12624 & 8894 & 2305 & 504 & \\
\hline Age, years & 50.7 & 48.0 & 46.3 & 45.7 & $<0.001$ \\
\hline Previous history of stroke, ischemic heart disease, or cancer, \% & 4.1 & 3.3 & 3.9 & 3.1 & 0.08 \\
\hline Current drinker, \% & 9.0 & 11.0 & 11.0 & 10.2 & $<0.001$ \\
\hline Current smoker, \% & 7.6 & 6.8 & 6.5 & 6.5 & 0.02 \\
\hline High perceived mental stress, \% & 18.5 & 22.8 & 29.3 & 40.9 & $<0.001$ \\
\hline Living with spouse, $\%$ & 69.6 & 81.6 & 81.6 & 83.2 & $<0.001$ \\
\hline Full-time worker, \% & 74.0 & 76.7 & 76.5 & 85.9 & $<0.001$ \\
\hline
\end{tabular}

current smoker); living with spouse (yes/no); and full-time worker (yes/no). We also calculated the HRs of suicide after the exclusion of persons with a previous history of stroke, ischemic heart disease, or cancer. To examine whether preclinical disorders and economic recession during the follow-up affected the association between educational levels and the risk of suicide, we calculated the HRs of suicide after the exclusion of suicidal deaths that occurred within 1 to 10 years of the baseline survey.

We tested the trends across educational levels using the ordinal numbers 0 to 3 assigned to the categories of educational levels. All statistical analyses were performed with SAS software version 9.4 (SAS Institute, Inc., Cary, NC, USA). All reported $P$-values were two-sided, and the significance level was set at $P<0.05$.

\section{RESULTS}

The sex-specific distributions of baseline characteristics according to the four categories of educational level are presented in Table 1. The participants were composed of $47.4 \%$ junior high school graduates, $38.7 \%$ high school graduates, $4.9 \%$ junior college graduates, and $9.0 \%$ university graduates or those with higher education in men; for women, the proportions were $51.9 \%, 36.6 \%, 9.5 \%$, and $2.1 \%$, respectively. Both men and women with higher educational levels were younger; more likely to have high perceived mental stress, live with a spouse, and be full-time workers; and less likely to be current smokers. Current drinkers were less common among junior high school graduates than among higher education graduates. Men with higher educational levels were less likely to have a previous history of stroke, ischemic heart disease, or cancer.
A total of 299 (218 men and 81 women) who died by suicide were documented during the median follow-up of 21.6 years. Table 2 shows sex-specific HRs of suicide according to educational levels. Age- and area-adjusted risk of suicide was lower in men with university graduation or higher education than in those with junior high school education. The multivariable HRs of suicide for university graduates or those with higher education compared with those of junior high school graduates after further adjustment for other potential confounding variables were $0.47(95 \% \mathrm{CI}$, 0.24-0.94) for all men, $0.43(95 \% \mathrm{CI}, 0.17-1.08)$ for men aged 40 to 49 years, and 0.64 ( $95 \%$ CI, $0.23-1.78$ ) for men aged 50 to 59 years. The corresponding HRs after the exclusion of persons with a previous history of stroke, ischemic heart disease, or cancer at the baseline survey were 0.48 (95\% CI, 0.24-0.97), 0.44 (95\% CI, 0.17-1.10), and 0.67 (95\% CI, 0.24-1.89).

Age- and area-adjusted risk of suicide was lower in women who graduated high school than in those who only graduated junior high school. The multivariable HRs of suicide for high school graduates compared with those of junior high school graduates after further adjustment for other potential confounding variables were 0.44 (95\% CI, $0.24-0.79)$ for all women, $0.21(95 \% \mathrm{CI}, 0.07-0.65)$ for women aged 40 to 49 years, and $0.60(95 \% \mathrm{CI}, 0.30-1.19)$ for women aged 50 to 59 years. The corresponding HRs after the exclusion of persons with a previous history of stroke, ischemic heart disease, or cancer at the baseline survey were $0.41(95 \% \mathrm{CI}$, $0.22-0.76), 0.21$ (95\% CI, 0.07-0.65), and 0.56 (95\% CI, $0.26-1.15)$.

Figure illustrates the sex-specific HRs of suicide for those with higher education after the exclusion of early suicidal deaths that occurred within 1 to 10 years of the baseline 
Table 2. Sex-specific hazard ratios of suicide according to educational levels

\begin{tabular}{|c|c|c|c|c|c|c|c|c|}
\hline & \multicolumn{4}{|c|}{ Men } & \multicolumn{4}{|c|}{ Women } \\
\hline & $\begin{array}{l}\text { Junior high } \\
\text { school }\end{array}$ & High school & $\begin{array}{l}\text { Junior or career } \\
\text { college }\end{array}$ & $\begin{array}{l}\text { University or higher } \\
\text { education }\end{array}$ & $\begin{array}{l}\text { Junior high } \\
\text { school }\end{array}$ & High school & $\begin{array}{l}\text { Junior or career } \\
\text { college }\end{array}$ & $\begin{array}{l}\text { University or higher } \\
\text { education }\end{array}$ \\
\hline \multicolumn{9}{|l|}{ All ages of $40-59$ years } \\
\hline Person-years & 202414 & 168847 & 21517 & 39276 & 259699 & 182585 & 47301 & 10257 \\
\hline Number of suicides & 119 & 79 & 11 & 9 & 60 & 15 & 5 & 1 \\
\hline Hazard ratio $(95 \% \mathrm{Cl})^{\mathrm{a}}$ & 1.00 & $0.85(0.64-1.15)$ & $0.95(0.51-1.76)$ & $0.43(0.22-0.85)$ & 1.00 & $0.44(0.24-0.79)$ & $0.58(0.23-1.46)$ & $0.57(0.08-4.15)$ \\
\hline Hazard ratio $(95 \% \mathrm{Cl})^{\mathrm{b}}$ & 1.00 & $0.91(0.67-1.22)$ & $1.01(0.54-1.90)$ & $0.47(0.24-0.94)$ & 1.00 & $0.44(0.24-0.79)$ & $0.56(0.22-1.43)$ & $0.55(0.08-4.03)$ \\
\hline \multicolumn{9}{|l|}{ Ages $40-49$ years } \\
\hline Person-years & 83716 & 96233 & 13349 & 25767 & 100700 & 101890 & 31399 & 7539 \\
\hline Number of suicides & 54 & 50 & 8 & 5 & 18 & 4 & 3 & - \\
\hline Hazard ratio $(95 \% \mathrm{Cl})^{\mathrm{a}}$ & 1.00 & $0.89(0.60-1.32)$ & $1.16(0.55-2.46)$ & $0.39(0.15-0.97)$ & 1.00 & $0.21(0.07-0.63)$ & $0.51(0.15-1.79)$ & - \\
\hline Hazard ratio $(95 \% \mathrm{Cl})^{\mathrm{b}}$ & 1.00 & $0.92(0.62-1.38)$ & $1.26(0.59-2.69)$ & $0.43(0.17-1.08)$ & 1.00 & $0.21(0.07-0.65)$ & $0.51(0.14-1.81)$ & - \\
\hline \multicolumn{9}{|l|}{ Ages $50-59$ years } \\
\hline Person-years & 118698 & 72615 & 8168 & 13509 & 158999 & 80695 & 15902 & 2718 \\
\hline Number of suicides & 65 & 29 & 3 & 4 & 42 & 11 & 2 & 1 \\
\hline Hazard ratio $(95 \% \mathrm{Cl})^{\mathrm{a}}$ & 1.00 & $0.81(0.52-1.27)$ & $0.69(0.22-2.21)$ & $0.58(0.21-1.61)$ & 1.00 & $0.61(0.31-1.21)$ & $0.51(0.12-2.14)$ & $1.40(0.19-10.2)$ \\
\hline Hazard ratio $(95 \% \mathrm{Cl})^{\mathrm{b}}$ & 1.00 & $0.87(0.55-1.38)$ & $0.70(0.22-2.26)$ & $0.64(0.23-1.78)$ & 1.00 & $0.60(0.30-1.19)$ & $0.49(0.12-2.03)$ & $1.30(0.18-9.60)$ \\
\hline
\end{tabular}

$\mathrm{Cl}$, confidence interval.

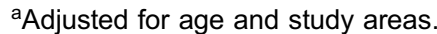

${ }^{b}$ Adjusted further for previous history of stroke, ischemic heart disease, or cancer (yes/no), perceived mental stress (mild, moderate, or severe), alcohol consumption (nondrinker, occasional drinker, or current drinker), smoking status (never, ex-, or current smoker), living with spouse (yes/no), and full-time worker (yes/no).

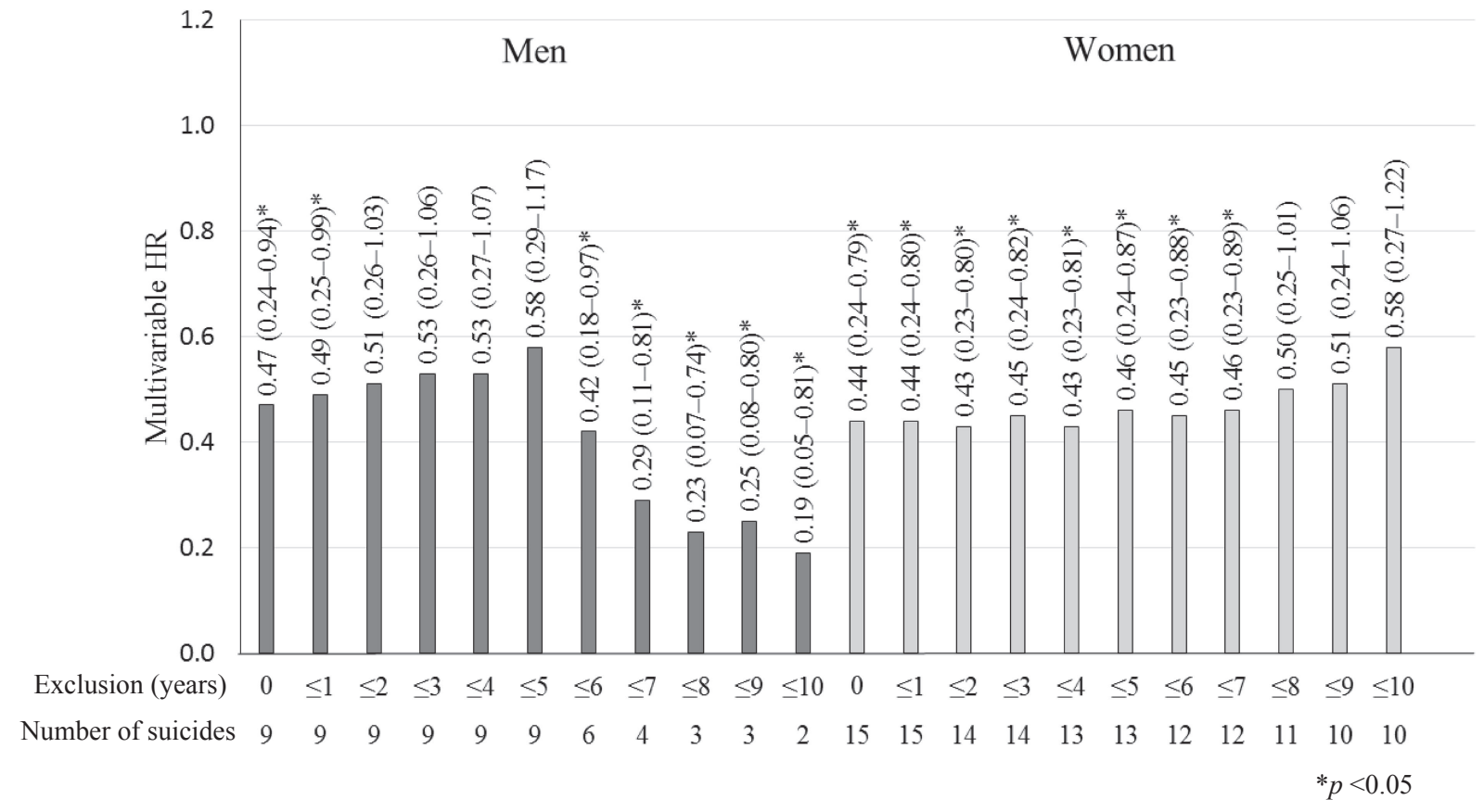

Figure. The sex-specific HRs and $95 \% \mathrm{Cls}$ of suicide for those with higher education compared to those with junior high school graduates after the exclusion of early suicidal deaths that occurred within 1 to 10 years of the baseline survey. $\mathrm{Cl}$, confidence interval; HR, hazard ratio.

survey. Compared with junior high school graduates, male university graduates or those with higher education and female high school graduates had a persistently lower risk of suicide.

\section{DISCUSSION}

In this large prospective study, we found that higher educational levels were associated with a lower risk of suicide for both men and women. The risk of suicide was approximately 50\% lower among male university graduates or those with higher education than among male junior high school graduates. The risk of suicide was approximately $60 \%$ lower among female high school graduates than among female junior high school graduates. The risk difference by educational levels was more pronounced for men and women aged 40 to 49 years than for those aged 50 to 59 years. To our knowledge, this is the first population-based prospective study 
in Japan to examine the association between educational levels and the risk of suicide after controlling for individual lifestyles and socioeconomic factors.

Depression is a well-known risk factor for suicide. ${ }^{17-19}$ Unfortunately, we did not have any information on depression; however, we did collect information on mental stress. Since persons with higher educational levels were likely to have higher perceived mental stress in the present study, the association between higher educational levels and a lower risk of suicide was unlikely to be explained by mental stress. Moreover, we analyzed the risk of suicide after the exclusion of early suicidal deaths that occurred within 1 to 10 years of the baseline survey; however, the association between higher educational levels and a lower risk of suicide did not change substantially when these suicidal deaths were excluded.

During the follow-up, major recessions in Japan occurred between 1991 and 1993 and between 1997 and 1999. ${ }^{20}$ The rate of suicide increased temporally among middle-aged men between 1998 and 2011. 2,21 In the present study, however, the HRs of suicide after the exclusion of suicidal deaths that occurred within 1 to 10 years of the baseline survey did not change substantially. This finding suggests that the economic recessions were unlikely to have influenced the association between educational levels and the risk of suicide in our study.

Although the mechanisms behind the association between educational levels and the risk of suicide are not clear, a possible explanation can be supposed. Low serum cholesterol levels have been shown to be associated with the risk of suicide, likely through lower serotonin levels in blood and brain circulation. $^{22-24}$ This explanation is supported by our finding that men with higher educational levels had higher age-adjusted mean values of total serum cholesterol than male junior high school graduates; in our subsamples of men $(n=6988)$, mean cholesterol levels were $194 \mathrm{mg} / \mathrm{dL}$ for junior high school graduates, $195 \mathrm{mg} / \mathrm{dL}$ for high school graduates, $195 \mathrm{mg} / \mathrm{dL}$ for junior or career college graduates, and $200 \mathrm{mg} / \mathrm{dL}$ for university graduates or those with higher education ( $P$ for difference $<0.001$ ); however, this explanation would not be applicable to women because the respective mean values of cholesterol among women $(n=11663)$ in our study were $201 \mathrm{mg} / \mathrm{dL}, 203 \mathrm{mg} / \mathrm{dL}, 203 \mathrm{mg} / \mathrm{dL}$, and $199 \mathrm{mg} / \mathrm{dL}$ ( $P$ for difference $<0.001$ ).

Our findings are consistent with the results from a Japanese autopsy study, ${ }^{15}$ a European comparative study (concerning men), ${ }^{13}$ and an American cohort study, ${ }^{12}$ but not with the results from an Italian nationwide register study (concerning both men and women) ${ }^{14}$ and the European comparative study (concerning women), ${ }^{13}$ which showed that higher educational levels are associated with a higher risk of suicide.

Until recently, Japanese women have generally dropped their careers to raise children or to concentrate on domestic duties. ${ }^{25}$ Therefore, they are unlikely to be influenced by their own employment status or income, and are more likely to be influenced by educational levels as the primary exposure of socioeconomic status. The discrepancy between the results of our study and those of the Italian study ${ }^{14}$ may be explained in part by the limited comparability with the Italian nationwide register study, as described in the introduction. The discrepancy may also be explained by the different employment systems between Japan and Italy. The employment system in Japan in the 1990s was primarily based on lifetime employment and seniority, especially for workers with higher educational levels. Italian workers with higher educational levels, however, may have had stronger psychological reactions under higher mental stress than those with lower educational levels. ${ }^{14}$ Different impacts of educational levels on health due to race or ethnicity, although not identified, could also have led to the discrepancy. ${ }^{26,27}$

The major strengths of the present study are its populationbased prospective design, large sample size, and adjustment for potential confounding variables. However, there are several limitations. First, the number of suicides was small, but the expected statistical power was acceptable for men (although not for women). Second, our subjects were overall less educated compared with national samples because our surveyed communities were primarily located in rural areas. In our study population, the educational levels were composed of $50 \%$ junior high school graduates, $38 \%$ high school graduates, $7 \%$ junior college graduates, and 5\% university graduates or those with higher education, while the corresponding proportions for national samples are $34 \%$, $49 \%, 6 \%$, and $11 \%{ }^{28}$ Therefore, it is uncertain whether our findings are generalizable to urban populations, and further studies in urban populations or nationally representative samples are needed. Third, the educational system in Japan changed in 1947. After World War II, the Fundamental Law of Education and the School Education Law forced the educational system to change from dual-track to single-track. Therefore, we analyzed the data stratified by age 40 to 49 and 50 to 59. For men and women, the inverse association between educational levels and the risk of suicide tended to be more evident in ages 40 to 49 than in ages 50 to 59 . This finding may be explained by the large heterogeneity of educational levels in each educational category in the previous dual-track system, which may have diluted the association between educational levels and the risk of suicide. Fourth, we did not have data on mental illness. Someone who had developed a mental illness in early adolescence (eg, schizophrenia) would have been unlikely to obtain higher education, but it would also have been unlikely for them to participate in our study at the ages of 40 to 69 years. Finally, we did not have data on income levels, home ownership, and other economic factors. A European comparative study indicated that the lack of home ownership is more strongly associated with the risk of suicide than low educational levels. ${ }^{13}$ Among our study participants, however, the number of those lacking home ownership may have been very small. 
In conclusion, high educational levels among Japanese men and women are associated with a reduced risk of suicide, suggesting that higher educational levels may have a protective role against suicide risk in Japanese society.

\section{ONLINE ONLY MATERIAL}

Abstract in Japanese.

\section{ACKNOWLEDGEMENT}

This study was supported by National Cancer Center Research and Development Fund (23-A-31[toku] and 26-A-2) (since 2011) and a Grant-in-Aid for Cancer Research from the Ministry of Health, Labour and Welfare of Japan (from 1989 to 2010).

Conflicts of interest: None declared.

\section{The JPHC Study Group}

Members of the JPHC Study Group are: S. Tsugane (principal investigator), N. Sawada, M. Iwasaki, S. Sasazuki, T. Yamaji, T. Shimazu and T. Hanaoka, National Cancer Center, Tokyo; J. Ogata, S. Baba, T. Mannami, A. Okayama, and Y. Kokubo, National Cerebral and Cardiovascular Center, Osaka; K. Miyakawa, F. Saito, A. Koizumi, Y. Sano, I. Hashimoto, T. Ikuta, Y. Tanaba, H. Sato, Y. Roppongi, and T. Takashima, Iwate Prefectural Ninohe Public Health Center, Iwate; Y. Miyajima, N. Suzuki, S. Nagasawa, Y. Furusugi, N. Nagai, Y. Ito, S. Komatsu and T. Minamizawa, Akita Prefectural Yokote Public Health Center, Akita; H. Sanada, Y. Hatayama, F. Kobayashi, H. Uchino, Y. Shirai, T. Kondo, R. Sasaki, Y. Watanabe, Y. Miyagawa, Y. Kobayashi, M. Machida, K. Kobayashi and M. Tsukada, Nagano Prefectural Saku Public Health Center, Nagano; Y. Kishimoto, E. Takara, T. Fukuyama, M. Kinjo, M. Irei, and H. Sakiyama, Okinawa Prefectural Chubu Public Health Center, Okinawa; K. Imoto, H. Yazawa, T. Seo, A. Seiko, F. Ito, F. Shoji and R. Saito, Katsushika Public Health Center, Tokyo; A. Murata, K. Minato, K. Motegi, T. Fujieda and S. Yamato, Ibaraki Prefectural Mito Public Health Center, Ibaraki; K. Matsui, T. Abe, M. Katagiri, M. Suzuki, K. and Matsui, Niigata Prefectural Kashiwazaki and Nagaoka Public Health Center, Niigata; M. Doi, A. Terao, Y. Ishikawa, and T. Tagami, Kochi Prefectural Chuo-higashi Public Health Center, Kochi; H. Sueta, H. Doi, M. Urata, N. Okamoto, and F. Ide and H. Goto, Nagasaki Prefectural Kamigoto Public Health Center, Nagasaki; H. Sakiyama, N. Onga, H. Takaesu, M. Uehara, T. Nakasone and M. Yamakawa, Okinawa Prefectural Miyako Public Health Center, Okinawa; F. Horii, I. Asano, H. Yamaguchi, K. Aoki, S. Maruyama, M. Ichii, and M. Takano, Osaka Prefectural Suita Public Health Center, Osaka; Y. Tsubono, Tohoku University, Miyagi; K. Suzuki, Research Institute for Brain and Blood Vessels Akita, Akita; Y. Honda, K. Yamagishi, S. Sakurai and N. Tsuchiya,
University of Tsukuba, Ibaraki; M. Kabuto, National Institute for Environmental Studies, Ibaraki; M. Yamaguchi, Y. Matsumura, S. Sasaki, and S. Watanabe, National Institute of Health and Nutrition, Tokyo; M. Akabane, Tokyo University of Agriculture, Tokyo; T. Kadowaki and M. Inoue, The University of Tokyo, Tokyo; M. Noda and T. Mizoue, National Center for Global Health and Medicine, Tokyo; Y. Kawaguchi, Tokyo Medical and Dental University, Tokyo; Y. Takashima and Y. Yoshida, Kyorin University, Tokyo; K. Nakamura and R. Takachi, Niigata University, Niigata; J. Ishihara, Sagami Women's University, Kanagawa; S. Matsushima and S. Natsukawa, Saku General Hospital, Nagano; H. Shimizu, Sakihae Institute, Gifu; H. Sugimura, Hamamatsu University School of Medicine, Shizuoka; S. Tominaga, Aichi Cancer Center, Aichi; N. Hamajima, Nagoya University, Aichi; H. Iso and T. Sobue, Osaka University, Osaka; M. Iida, W. Ajiki, and A. Ioka, Osaka Medical Center for Cancer and Cardiovascular Disease, Osaka; S. Sato, Chiba Prefectural Institute of Public Health, Chiba; E. Maruyama, Kobe University, Hyogo; M. Konishi, K. Okada, and I. Saito, Ehime University, Ehime; N. Yasuda, Kochi University, Kochi; S. Kono, Kyushu University, Fukuoka; and S. Akiba, Kagoshima University, Kagoshima.

\section{REFERENCES}

1. WHO. Suicide. World Health Organization; [cited 2015 Feb 4]; Available from: http:/www.who.int/mediacentre/factsheets/ fs398/en/.

2. Chen J, Choi YJ, Sawada Y. How is suicide different in Japan? Japan World Econ. 2009;21:140-50.

3. Cantor CH, Slater PJ, Najman JM. Socioeconomic indices and suicide rate in Queensland. Aust J Public Health. 1995;19: 417-20.

4. Milner A, McClure R, De Leo D. Socio-economic determinants of suicide: an ecological analysis of 35 countries. Soc Psychiatry Psychiatr Epidemiol. 2012;47:19-27.

5. Wang N, Iwasaki M, Otani T, Hayashi R, Miyazaki H, Xiao L, et al. Perceived health as related to income, socio-economic status, lifestyle, and social support factors in a middle-aged Japanese. J Epidemiol. 2005;15:155-62.

6. Lewis G, Sloggett A. Suicide, deprivation, and unemployment: record linkage study. BMJ. 1998;317:1283-6.

7. Agerbo E, Qin P, Mortensen PB. Psychiatric illness, socioeconomic status, and marital status in people committing suicide: a matched case-sibling-control study. J Epidemiol Community Health. 2006;60:776-81.

8. Qin P, Agerbo E, Mortensen PB. Suicide risk in relation to socioeconomic, demographic, psychiatric, and familial factors: A national register-based study of all suicides in Denmark, 1981-1997. Am J Psychiatry. 2003;160:765-72.

9. Agerbo E, Gunnell D, Bonde JP, Mortensen PB, Nordentoft M. Suicide and occupation: the impact of socio-economic, demographic and psychiatric differences. Psychol Med. 2007;37: 1131-40.

10. Burnley IH. Socioeconomic and spatial differentials in mortality 
and means of committing suicide in New South Wales, Australia, 1985-91. Soc Sci Med. 1995;41:687-98.

11. Poudel-Tandukar K, Nanri A, Mizoue T, Matsushita Y, Takahashi Y, Noda $\mathrm{M}$, et al. Differences in suicide risk according to living arrangements in Japanese men and women-the Japan Public Health Center-based (JPHC) prospective study. J Affect Disord. 2011;131:113-9.

12. Denney JT, Rogers RG, Krueger PM, Wadsworth T. Adult suicide mortality in the United States: marital status, family size, socioeconomic status, and differences by sex. Soc Sci Q. 2009;90:1167.

13. Lorant V, Kunst AE, Huisman M, Costa G, Mackenbach J; EU Working Group on Socio-Economic Inequalities in Health. Socio-economic inequalities in suicide: a European comparative study. Br J Psychiatry. 2005;187:49-54.

14. Pompili M, Vichi M, Qin P, Innamorati M, De Leo D, Girardi P. Does the level of education influence completed suicide? A nationwide register study. J Affect Disord. 2013;147:437-40.

15. Hirokawa S, Kawakami N, Matsumoto T, Inagaki A, Eguchi N, Tsuchiya M, et al. Mental disorders and suicide in Japan: a nation-wide psychological autopsy case-control study. J Affect Disord. 2012;140:168-75.

16. Tsugane S, Sobue T. Baseline survey of JPHC study - design and participation rate. Japan Public Health Center-based Prospective Study on Cancer and Cardiovascular Diseases. J Epidemiol. 2001;11:24-9.

17. Harris EC, Barraclough B. Suicide as an outcome for mental disorders. A meta-analysis. Br J Psychiatry. 1997;170:205-28.

18. Hawton K, Casañas I, Comabella C, Haw C, Saunders K. Risk factors for suicide in individuals with depression: a systematic review. J Affect Disord. 2013;147:17-28.

19. Nishi N, Kurosawa M, Nohara M, Oguri S, Chida F, Otsuka K, et al. Knowledge of and attitudes toward suicide and depression among Japanese in municipalities with high suicide rates. J Epidemiol. 2005;15:48-55.

20. The determination of Business-Cycle Peak and Trough [Internet]. Cabinet Office. Available from: http://www.esri.cao. go.jp/en/stat/di/111019rdates.html.

21. 2013 White paper on Suicide Prevention in Japan-Digest version [Internet]. Cabinet Office. Available from: http:/ www8.cao.go.jp/jisatsutaisaku/whitepaper/w-2013/html/honpen/ chapter1-03.html.

22. Engelberg H. Low serum cholesterol and suicide. Lancet. 1992;339:727-9.

23. Golier JA, Marzuk PM, Leon AC, Weiner C, Tardiff K. Low serum cholesterol level and attempted suicide. Am J Psychiatry. 1995;152:419-23.

24. Zureik M, Courbon D, Ducimetière P. Serum cholesterol concentration and death from suicide in men: Paris prospective study I. BMJ. 1996;313:649-51.

25. Honjo K, Iso H, Inoue M, Sawada N, Tsugane S; JPHC Study Group. Socioeconomic status inconsistency and risk of stroke among Japanese middle-aged women. Stroke. 2014;45:2592-8.

26. Bartley M. Health inequality. An introduction to theories, concepts and methods. Cambridge, England: Polity Press; 2004.

27. Krieger N, Williams DR, Moss NE. Measuring social class in US public health research: concepts, methodologies, and guidelines. Annu Rev Public Health. 1997;18:341-78.

28. Statistic Breau M and CA. 1990 population census of Japan. Statistic Breau, Management and Coordination Agency; 1993. 